\title{
PRE-DONATION SCREENING OF BLOOD FOR TRANSFUSION TRANSMISSIBLE INFECTIONS: THE GAINS AND THE PAINS - EXPE- RIENCE AT A RESOURCE LIMITED BLOOD BANK.
}

\author{
A.O. SHITTU, H.O. OLAWUMI and J.O. ADEWUYI \\ Department of Haematology and Blood Transfusion, University of Ilorin
}

DOI: http://dx.doi.org/10.4314/gmj.v48i3.8

Corresponding Author: Dr. A.O. Shittu

Email:drakeem06@yahoo.com

Conflict of Interest: None declared

\begin{abstract}
SUMMARY
Objective: To determine whether or not pre-donation testing of blood donors affords substantial cost savings without compromise to blood transfusion safety. Predonation testing of blood donors for Transfusion Transmissible Infections (TTIs) is done in most developing countries because substantial cost savings are made from resources, materials and man-hours which would have been spent to procure infected blood units. Simple rapid test kits used in pre-donation testing is not as sensitive as the Enzyme Linked Immuno-sorbent Assay (ELISA) method used in post-donation screening in a quality assured manner.

Design: It is a retrospective study where records of pre- and post-donation tests done in donor clinic of University of Ilorin Teaching Hospital, between January and December 2010 were retrieved. All processes and inputs were evaluated and costs calculated for predonation testing by simple rapid techniques and post donation screening by ELISA.

Results: 5000 prospective donors were tested in the study period. The cost of single rapid Pre-donation testing was less than that of single ELISA Postdonation screen. The cost of double rapid Pre-donation and Post donation ELISA screen exceeded the cost of single post donation ELISA screen. Substantial cost savings were made when single rapid Pre-donation testing is relied on. More blood units were found reactive for the TTIs with the more expensive Postdonation ELISA.

Conclusion: Pre-donation testing of blood donors was not cost effective. Although, there is an apparent savings if pre-donation testing is not followed by postdonation ELISA testing, it is done at a compromise to blood transfusion safety.
\end{abstract}

Key words: pre-donation, post-donation, TTIs screening.

\section{INTRODUCTION}

Pre-donation screening of blood donors for Transfusion Transmissible Infections (TTI) is the practice by which a prospective donor is tested for the presence of one or more of the TTI agents by a single rapid or quick method, and donation is deferred if the test is reactive for any of the TTI markers. Universally the normal procedure is to administer a standard questionnaire, measure the haemoglobin concentration and the weight of the donor1. The donor is then bled if found fit based on the selection criteria and asked to leave after a period of rest. The donor units are then separated into various components and stored. A third generation ELISA batch analyzer is used to test samples of corresponding donated units. All those non-reactive for viral markers are appropriately labeled and used for transfusion. Those reactive for any of the TTIs are appropriately discarded, including their respective components.

Hepatitis B virus (HBV), hepatitis C virus (HCV), Human immune deficiency virus (HIV) and syphilis are the most important agents causing transfusion transmitted infections (TTIs) and they constitute large health care burdens worldwide. Because of their latent nature prior to clinical presentation, their incidence rates are difficult to calculate. ${ }^{1}$ Every blood transfusion therefore carries a potential risk for transmissible diseases. ${ }^{1,2}$

The blood supply and transfusion practice in the United State is one of the safest in the world because they have been based on a combination of strategies including effective donor education and donor recruitment, and collection of blood from repeat voluntary donors, donor retention, pre- and post-donation counseling, donation screening using the most sensitive and specific screening kits and recent laboratory procedures performed in a quality assured manner. 
Therefore, the risks of TTIs are extremely low ${ }^{3}$. It is estimated to be about 1 in 677,000 units of blood for $\mathrm{HIV}^{4}, 1$ in 103,000 units for hepatitis $\mathrm{C}$ virus and 1 in 63,000 units for hepatitis B virus. ${ }^{3}$

Various integrate measures are put in place to make blood transfusion safe. These measures include the recruitment of voluntary non-remunerated donors; effective donor education and careful donor selection; and the use of sensitive laboratory screening of donated blood. ${ }^{5}$ These measures together have resulted in a very low residual risk for TTIs. ${ }^{6}$ Comparable results for TTIs risks are found in most developed countries. In Australia the risks are 1 in 633,000 units for $\mathrm{HBV}, 1$ in 6,387,000 units for HCV and 1 in 9,242,000 units for HIV. $^{7}$

The objective of pre-donation TTI testing is to save resources, materials and man-hours which would have been spent to procure donor blood which could not be used in therapy and reduce the discard rate of donated blood. By performing pre-donation testing the infected prospective donor is spared the trouble of going through the donation process unnecessarily and the discard rate of donated blood is reduced. Pre-donation TTI testing is the standard practice in many Hospitalbased blood transfusion services in developing countries like Nigeria.

A major consumable for blood collection is the imported blood bag hence pre-donation testing and deferral of unsuitable prospective donor/s is assumed to produce substantial cost savings on procurement of blood bags. It appears however that the basis for such assumption has not been clearly established. All related financial costs and the implications for blood safety must be factored in to justify routine Pre-donation testing of blood donors. This study was carried out to establish whether or not Pre-donation testing affords substantial cost savings without compromise to blood safety.

\section{MATERIALS AND METHODS}

In the University of Ilorin Teaching Hospital, predonation TTI testing is done after the prospective donor has passed the haemoglobin check. Two rapid test systems are used to test for HIV, namely Determine and Unigold. The single rapid kit used for testing HBsAg is the ACON while Diaspot is used for testing $\mathrm{HCV}$. Donation is deferred when the blood sample of a prospective donor is reactive for any of the TTI markers. Blood donated by donors found non-reactive on pre-donation TTI testing is later subjected in batches to routine Post-donation ELISA testing for the three TTI markers.
Transfusion transmissible infections

All records of Pre and Post-donation tests carried out in the donor clinic of University of Ilorin Teaching Hospital between January and December 2010 were reviewed. All processes and inputs were evaluated. Costs were calculated for Pre-donation testing by simple rapid techniques and Post-donation testing by ELISA for blood samples from all prospective donors.

The compared costs were also computed for both Predonation testing of all prospective donors and Postdonation testing of blood samples of donors who eventually donated blood. All costs were compared.

We also compared the number of samples that were reactive with rapid testing and the number that were reactive with ELISA.

\section{RAPID TEST KITS}

DETERMINE (Inverness Medical Japan Co. Ltd) is an immunochromatographic test for the qualitative detection of antibodies to HIV-1 and HIV-2.

UNIGOLD (by Trinity Biotech Plc, Ireland) is a single reagent assay for the detection of antibodies to HIV-1 and 2 in serum, plasma or whole blood.

ACON (ACON Laboratories, Inc, San Diego, USA) is a qualitative, solid phase, two-site sandwich immunoassay for the detection of HBsAgs in whole blood, serum or plasma.

DIASPOT (Reagent by USA) is also a qualitative, membrane based immunoassay for the detection of antibody to $\mathrm{HCV}$ in serum or plasma.

\section{ELISA TEST KITS}

GENSCREEN PLUS HIV Ag-Ab (Bio-Rad, Raymond Poincare 92430, Marnes Coquettes and France) is an enzyme immunoassay for the detection of HIV infection, based on the detection of antibodies to HIV 1 and 2 and the HIV 1 Ag in human serum or plasma.

MONOLISA HBsAg ULTRA (Bio-Rad, Raymond Poincare 92430, Marnes Coquette, France) is a onestep enzyme immunoassay based on the principle of the sandwich type using monoclonal antibodies and polyclonal antibodies selected for their ability to bind themselves to the various subtypes of HBsAg now recognized by WHO and the most part of variant HBV strains.

\section{RESULTS}

Approximately 5000 prospective donors presented at UITH donor clinic between January and December 2010 and were tested. Eight hundred (800) of these prospective donors were deferred after simple rapid testing. 
Table 1 shows the unit costs of various inputs required for different testing methods for TTIs in Nigeria Naira $(\mathrm{N})$ and in US Dollar (\$).

Table 1 Unit cost of various inputs required for simple rapid testing and ELISA screening at UITH.

\begin{tabular}{|l|l|}
\hline $\begin{array}{l}\text { Cost of HIV simple rapid screen/unit by Deter- } \\
\text { mine }\end{array}$ & N100 (\$0.62) \\
\hline $\begin{array}{l}\text { Cost of HIV simple rapid screen/unit by Uni- } \\
\text { gold }\end{array}$ & $\mathrm{N} 250(\$ 1.5)$ \\
\hline Cost of HBsAg simple rapid screen/unit & $\mathrm{N} 80(\$ 0.5)$ \\
\hline Cost of HCV simple rapid screen/unit & $\mathrm{N} 70(\$ 0.4)$ \\
\hline Cost of HIV ELISA/unit & $\mathrm{N} 945(\$ 5.7)$ \\
\hline Cost of HBsAg ELISA/unit & $\mathrm{N} 600(\$ 3.6)$ \\
\hline Cost of HCV ELISA/unit & $\mathrm{N} 600(\$ 3.6)$ \\
\hline Cost of Blood bag/unit & $\mathrm{N} 200(\$ 1.2)$ \\
\hline Cost of consumable/unit & $\mathrm{N} 100(\$ 0.6)$ \\
\hline
\end{tabular}

Three million eight hundred and forty thousand naira $(\mathrm{N} 3,840,000(\$ 23,040))$ was the cost of pre-donation screening by rapid method for 5000 prospective donors, Table 2.

Twelve million eight hundred and forty nine thousand Naira $(\mathrm{N} 12,849,000(77,094))$ was the total cost for pre-donation screen of the 5000 prospective donors in addition to post-donation ELISA testing of 4200 blood samples from respective donors who were found suitable to donate, Table 2 .

Twelve million two hundred and twenty five thousand Naira $(\mathrm{N} 12,225,000(\$ 73,350))$ was the total cost for ELISA testing without pre-donation screen of all the 5000 prospective donors, Table 2 .

In UITH, approximately $75 \%$ of all donated blood is used on emergencies. Three million two hundred and sixty five thousand two hundred and fifty Naira (N3, $265,250(\$ 19,592))$ was the total cost for post-donation ELISA screening of samples of donated units remaining after emergency use, Table 3

Table 2 Total cost expended with simple rapid pre-donation testing only, simple rapid pre-donation testing plus ELISA and ELISA screening only.

\begin{tabular}{|c|c|c|c|c|c|}
\hline \multicolumn{2}{|c|}{$\begin{array}{l}\text { Simple rapid pre-donation testing of } \\
\text { blood donors only }\end{array}$} & \multicolumn{2}{|c|}{$\begin{array}{l}\text { Simple rapid pre-donation testing of } \\
\text { blood donors plus ELISA screen of } \\
\text { donated blood units }\end{array}$} & \multicolumn{2}{|c|}{$\begin{array}{l}\text { Pos-donation ELISA screen of donat- } \\
\text { ed blood units }\end{array}$} \\
\hline Procedure & Amount N(\$) & Procedure & Amount N(\$) & Procedure & Amount N(\$) \\
\hline $\begin{array}{l}\text { Pre-donation } \\
\text { screen of 5000@ } \\
\text { N500 (\$3) }\end{array}$ & $\begin{array}{l}\mathrm{N} 2,500,000 \\
(\$ 15,000)\end{array}$ & $\begin{array}{l}\text { Pre-donation } \\
\text { screen of } 5000 @ \text { @ } \\
\text { N500 (\$3) }\end{array}$ & $\begin{array}{l}\mathrm{N} 2,500,000 \\
(\$ 15,000)\end{array}$ & $\begin{array}{l}\text { ELISA for } 5000 \\
\text { (a) } \mathrm{N} 2,145(\$ 13)\end{array}$ & $\begin{array}{l}\mathrm{N} 10,725,000 \\
(\$ 64,350)\end{array}$ \\
\hline 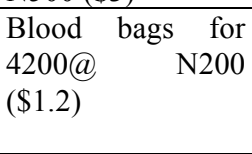 & $\mathrm{N} 840,000(\$ 5,040)$ & $\begin{array}{l}\text { Post-donation } \\
\text { ELISA testing of } \\
4,200 @ \mathrm{~N} 2,145 \\
(\$ 13)\end{array}$ & $\begin{array}{l}\mathrm{N} 9,009,000 \\
(\$ 54,054)\end{array}$ & $\begin{array}{llr}\text { Blood } & \text { bags } & \text { for } \\
5000 & @ & \mathrm{~N} 200 \\
(\$ 1.2) & & \end{array}$ & $\begin{array}{l}\mathrm{N} 1,000,000 \\
(\$ 6,000)\end{array}$ \\
\hline $\begin{array}{l}\text { Consumables } \text { for } \\
5000 @ \quad \text { N100. } \\
(\$ 0.6)\end{array}$ & $\mathrm{N} 500,000(\$ 3,000)$ & $\begin{array}{l}\text { Blood bags for } \\
4,200 @ \mathrm{~N} 200(\$)\end{array}$ & $\mathrm{N} 840.000(\$ 5,040)$ & $\begin{array}{l}\text { Consumables } \text { for } \\
5000 @ \quad @ \quad N 100 \\
(\$ 0.6)\end{array}$ & N500,000 (\$3,000) \\
\hline TOTAL & $\begin{array}{l}\mathrm{N} 3,840,000 \\
(\$ 23,040)\end{array}$ & $\begin{array}{l}\text { Consumables } \text { for } \\
5000 @ \quad \text { N100 } \\
(\$ 0.6)\end{array}$ & $\mathrm{N} 500,000(\$ 3,000)$ & TOTAL & $\begin{array}{l}\text { N12,225,000 } \\
(\$ 73,350)\end{array}$ \\
\hline & & TOTAL & $\begin{array}{l}\text { N12,849,000 } \\
(\$ 77,094)\end{array}$ & & \\
\hline
\end{tabular}

Table 3 Cost expended on post-donation ELISA screening of 800 donated units found reactive to pre-donation simple rapid testing and ELISA screening of units remaining after emergency use.

\begin{tabular}{|l|l|l|l|}
\hline $\begin{array}{l}\text { Post-donation ELISA screening of 800 units found reac- } \\
\text { tive to simple rapid testing }\end{array}$ & $\begin{array}{l}\text { Post-donation ELISA screen of donated units remaining after } \\
\text { emergency use }\end{array}$ \\
\hline Procedure & Amount N(\$) & Procedure & Amount N(\$) \\
\hline ELISA for 800@ N2,145(\$13) & $\mathrm{N} 1,716,000(\$ 10,296)$ & ELISA for 1250 units @ N2,145(\$13) & $\mathrm{N} 2,681,250(\$ 16,088)$ \\
\hline Blood bags for 800@ N200(\$1.2) & $\mathrm{N} 160,000(\$ 960)$ & Blood bags for 4200 units @ N200 (\$1.2) & $\mathrm{N} 84,000(\$ 504)$ \\
\hline $\begin{array}{l}\text { Consumables for 800@ @100 } \\
\text { \$0.6) }\end{array}$ & $\mathrm{N} 80,000(\$ 480)$ & Consumables for 5000@ N100(\$0.6) & $\mathrm{N} 500,000(\$ 3,000)$ \\
\hline TOTAL & $\mathrm{N} 1,956,000(\$ 11,736)$ & TOTAL & $\mathrm{N} 3,265,250(\$ 19,592)$ \\
\hline
\end{tabular}


From Table 2 it is obvious that an excess cost of six hundred and twenty four thousand Naira (N624,000(\$3,744)) was made when post-donation ELISA screen of all donated blood followed predonation testing of all donors as compared with postdonation screen of all donated blood only. Also an apparent saving of nine million five hundred and eighty three thousand, seven hundred and fifty naira (N9, $583,750(\$ 57,503))$ was shown when approximately $75 \%$ of all the donated blood were used as emergency without further ELISA screen on them.

Eight hundred (800) out of 5000 samples (16\%) were reactive with simple rapid testing for the TTIs [259(5.2\%) for HIV 1and 2, 537(10.7\%) for HBsAg and $4(0.08 \%)$ for $\mathrm{HCV}]$ while $850(17 \%)$ [267(5.3\%) for HIV1 and 2, 574(11.5\%) for HBsAg and 9(0.2\%) for $\mathrm{HCV}$ ] eventually came out reactive with ELISA,

\section{DISCUSSION}

The result of this study shows that pre-donation testing of blood donors is not cost effective. For example, in order to save N160,000 (\$960) on blood bags for the 800 deferred donors, N2,520,000 $(\$ 15,120)$ was spent to screen, perhaps unnecessarily, the 4200 accepted donors. The alternative to pre-donation testing of blood donors is the post-donation screening of all donated blood by standard ELISA. The cost of ELISA testing for 5000 post donation samples is N12,225,000 $(\$ 73,350)$, compared to $\mathrm{N} 3,840,000(\$ 23,040)$ for predonation rapid testing of 5000 prospective donors.

Thus, a huge sum of N9,583,750 $(\$ 57,503)$ is apparently saved if pre-donation simple rapid testing is not followed by post donation ELISA testing of donated samples. When the cost of post-donation ELISA testing of blood samples of the 4200 accepted donors (N9,009,000 (\$54,054)) is added to the cost of predonation rapid testing of 5000 prospective donors $(\mathrm{N} 3,840,000(\$ 23,040))$, the total cost is $\mathrm{N} 12,849,000$ $(\$ 77,094)$. The cost of double rapid testing of donors and ELISA testing of donated samples exceeds the cost of single post-donation ELISA by N624,000 (\$3,744), while only N160,000 (960) is saved on blood bags, giving a deficit of $\mathrm{N} 464,000(\$ 2,784)$.

It is therefore apparent that if any saving is to be made, it is done at an incalculable cost of compromise to blood safety when reliance is placed only on predonation rapid TTI testing of blood donors. Our study further revealed that approximately $75 \%$ of donated blood is used for emergency transfusion before undergoing ELISA testing in our environment. This is what creates the false impression of savings by pre-donation testing of blood donors.
This is not the best practice of blood transfusion, in which reliance is placed on only rapid screening of prospective donors.

Literature comparing the total cost expended in preand post-donation testing for TTIs is very sparse, but several studies carried out have been for and against pre-donation TTI testing. ${ }^{8,9}$ Pre-donation testing has been found to be highly recommended in eliminating many potential risks for the donors, laboratory staff, blood recipients and their families and the overall society in Pakistan. ${ }^{8}$ Another study in Ghana recognized the importance of post donation screening when up to $3 \%$ of Hepatitis infected blood were tested positive with post donation sophisticated methods. In this study, they still recommended pre-donation testing of donors but with more sensitive and effective methods, donor screening with questionnaire before donation, donor information and counseling in high prevalence areas because the more sophisticated methods cannot be routinely available to all, in resource poor countries. ${ }^{9}$

Consensus on blood transfusion practice is the same despite varying statistics from various researches all over the world. That is donors are the vital links in the chain of transmission of TTIs via blood transfusion. Therefore careful selection using designed questionnaire, proper screening of the blood (pre- or postdonation) is the priority of all donations and overall transfusion services. With this, professionals in the field will be able to deliver safe end products.

\section{RECOMMENDATION}

It is therefore recommended that pre-donation TTI testing be abolished, and all donated blood be tested by routine ELISA method. However, in order to accommodate emergency use of blood, simple rapid testing of donors for TTIs may be done pre-donation in addition to ELISA testing of donated blood which should still be carried out post-donation. Patients who may have been transfused with blood showing discordant results must then be followed up and managed accordingly.

Apart from the financial loss incurred, pre-donation testing of blood donors is a form of inconvenience and time wasting to the prospective donor and can lead to discouragement of true voluntary donors. It should be mandatory to carry out the usual pre-donation selection using standard questionnaire and post donation screening of donated blood in all our blood banks.

Family replacement donation, which is the main form of donation in resource poor countries like ours and which contributed to the high prevalence of TTIs, should also be discouraged. 


\section{REFERRENCES}

1. Bhawani Y, Rao PR, Sudhakar V: Seroprevalence of transfusion transmissible infections among blood donors in a tertiary care hospital of Andhra Pradesh. Biol Med 2010, 2(4):45-48.

2. Khan S, Attaullah S, Ayaz S, Khan SN, Shams S, Ali I, Bilal M, Siraj S: Molecular epidemiology of $\mathrm{HCV}$ among the health care workers of Khyber Pakhtunkhwa. Virol J 2011,8(1):105.

3. Schreiber GB, Busch MP, Kleinman SH, Korelitz JJ. The risk of transfusion-transmitted viral infections. N Engl J Med. 1996; 334: 1685-1690.

4. Kleinman S, Busch MP, Korelitz JJ, Schreiber GB. The incidence/window period model and its use to assess the risk of transfusion-transmitted human immunodeficiency virus and hepatitis $\mathrm{C}$ virus infection. Transfus Med Rev. 1997; 11: 155-172.

5. World Health Organization. WHO Expert Committee on biological standardization, $54^{\text {th }}$ Report. Geneva : World Health Organization; 2005.
6. Seed CR, Kiely P, Keller AJ. Residual risk of transfusion transmitted human immunodeficiency virus, hepatitis $\mathrm{B}$ virus, hepatitis $\mathrm{C}$ virus and human T lymphotrophic virus. Intern Med J 2005; 35: 592-8.

7. Australian Red Cross Blood Service. Updated estimates of residual risks of transfusion transmitted infections. Medilink [serial on the Internet] 2006 [cited 2007 Apr 1] Dec

8. Lubna Naseem and Anwar UI Haque. Predonation Testing of the Potential Blood Donors A Pilot Study at a Tertiary Care Hospital. www.jpathology.com/issues/IJPissue 12/original article 4.

9. Ofori S O, Temple J, Sarkodie Fet al. Predonation screening of blood donors with rapid test. Transfusion 2005 45(2): 133-140. 